\title{
O Programa Bolsa Família e a educação: uma análise da produção científica brasileira fundamentada na base de dados SciELO (2003-2018)
}

\author{
Bárbara Amaral Martins' (D) \\ Fabiano Quadros Rückert'
}

\section{RESUMO}

O objetivo do estudo consiste em analisar uma amostra da produção científica brasileira divulgada em periódicos nacionais a respeito do Programa Bolsa Família e suas relações com a educação. Os dados analisados procedem de 11 trabalhos localizados na base Scientific Electronic Library Online e, no seu conjunto, oferecem um panorama dos temas, métodos, conceitos e problemas contemplados pelos pesquisadores que estudam o Programa Bolsa Família. Pela leitura dos trabalhos selecionados, identificamos cinco categorias temáticas. São elas: condicionalidade de educação; concepções sobre o programa; indicadores educacionais; distorção idade-série; e condições de oferta escolar. Os resultados do estudo indicam predomínio de abordagens quantitativas e a tendência de uso de metadados e apontam para uma incipiente preocupação com a percepção dos beneficiários acerca do programa e com a qualidade da educação oferecida em escolas com elevado índice de beneficiários.

PALAVRAS-CHAVE

Programa Bolsa Família; análise da produção científica; Brasil.

'Universidade Federal de Mato Grosso do Sul, Corumbá, Mato Grosso do Sul, Brasil. 


\title{
THE BOLSA FAMÍLIA PROGRAM AND EDUCATION: AN ANALYSIS OF BRAZILIAN SCIENTIFIC PRODUCTION FROM THE SCIELO DATABASE (2003-2018)
}

\begin{abstract}
The objective of the study was to analyze a sample of the Brazilian scientific production published in national scientific journals, regarding the Programa Bolsa Família (Bolsa Família Program) and its relations with Education. The data analyzed come from 11 works located in the Scientific Electronic Library Online, and, as a whole, offer an overview of the themes, methods, concepts and problems contemplated by the researchers studying the Programa Bolsa Família. From the reading of the selected works, we identified five thematic categories. These are: conditionality of education; conceptions about the program; educational indicators; age-series distortion; conditions of school supply. The results of the study indicate a predominance of quantitative approaches and a tendency to use metadata; and point to an incipient concern with the beneficiaries' perception of the program and the quality of the education offered in schools with a high beneficiary index.
\end{abstract}

\section{KEYWORDS}

Programa Bolsa Família; analysis of scientific production; Brazil.

\section{EL PROGRAMA BOLSA FAMILIA Y LA EDUCACIÓN: UN ANÁLISIS DE LA PRODUCCIÓN CIENTÍFICA BRASILEÑA DESDE LA BASE DE DATOS SCIELO (2003-2018)}

\section{RESUMEN}

El objetivo del estudio consiste en analizar una muestra de la producción científica brasileña divulgada en periódicos nacionales, sobre el Programa Bolsa Família (Programa Bolsa Familia) y sus relaciones con la Educación. Los datos analizados proceden de 11 trabajos ubicados en la base Scientific Electronic Library Online, y, en su conjunto, ofrecen un panorama de los temas, métodos, conceptos y problemas contemplados por los investigadores que estudian el Programa Bolsa Família. A partir de la lectura de los trabajos seleccionados, identificamos cinco categorías temáticas. Son ellas: condicionalidad de la educación; concepciones sobre el programa; indicadores educativos; distorsión edad-serie; condiciones de la oferta escolar. Los resultados del estudio indican un predominio de enfoques cuantitativos $\mathrm{y}$ una tendencia de uso de metadatos; $\mathrm{y}$ apuntan a una incipiente preocupación por la percepción de los beneficiarios del programa y la calidad de la educación ofrecida en escuelas con altas tasas de beneficiarios.

Programa Bolsa Família; análisis de la producción científica; Brasil. 


\section{INTRODUÇÃO}

A educação formal tem a finalidade de possibilitar aos indivíduos a apropriação dos conhecimentos historicamente construídos, de modo a impulsionar o desenvolvimento das funções psicológicas especificamente humanas, por meio da mediação (Vygotsky, 1981).

Considerando que o desenvolvimento humano é sociocultural, assume-se que o ambiente desempenha papel fundamental para a aquisição de conhecimentos e o aumento das capacidades cognitivas. Logo, privações sociais, econômicas e culturais podem inviabilizar o pleno desenvolvimento das potencialidades humanas.

O Brasil é um país afetado por acentuada desigualdade social, que coloca e mantém milhões de pessoas em situação pobreza. Segundo o Instituto Brasileiro de Geografia e Estatística (IBGE, 2018), o percentual de brasileiros pobres passou de $25,7 \%$ em 2016 para 26,5\% em 2017, representando, respectivamente, 52,8 e 54,8 milhões de pessoas que vivem com até $\mathrm{R} \$ 406,00$ por mês. Já a extrema pobreza, que abrange os cidadãos que sobrevivem com até $\mathrm{R} \$ 140,00$ por mês, afetou $6,6 \%$ da população em 2016 e 7,4\% em 2017, o que compreende, em números absolutos, 13,5 e 15,2 milhões de pessoas, nessa ordem.

Mais do que privações materiais, que envolvem a satisfação de direitos básicos, como alimentação e moradia, a pobreza tem reflexos culturais que interferem no desenvolvimento dos sujeitos, muitos dos quais deixam de frequentar a escola em busca de melhores condições para a sobrevivência. Como alternativa para amenizar os efeitos da pobreza, foram criados os programas de transferência de renda, ${ }^{1}$ entre os quais destacamos o Programa Bolsa Família.

Criado no ano de 2003 e sancionado pela lei n. 10.836/2004, o Programa Bolsa Família foi regulamentado pelo decreto n. 5.209, assinado em dezembro de 2004. Ele ganhou forma por meio da união de diversos programas federais de transferência de renda que foram gradualmente implantados desde a promulgação da Constituição Federal de 1988. Nesse sentido, o referido programa pode ser interpretado como um instrumento aprimorado de uma política de Estado voltada para garantir os mínimos direitos sociais e com foco na saúde e na educação.

Barrientos, Debowicz e Woolard (2016) constataram que o Bolsa Família produziu resultados positivos no que diz respeito à universalização do ensino escolar e no atendimento à saúde, no entanto eles afirmam que o programa não alterou o quadro de oferta de mão de obra adulta. Esses autores apresentam dados que ressaltam diferenças de ordem regional e de gênero nos efeitos do programa. Januzzi e Pinto (2013), por sua vez, apontam como aspectos positivos do programa a ocorrência de melhorias na imunidade, no peso por altura e na massa corporal das crianças; a redução nos índices de reprovação de série; o atraso do ingresso das crianças no mercado de trabalho; e o aumento de visitas pré-natais.

1 Existe uma ampla bibliografia que discute os programas de transferência de renda levando em conta aspectos jurídicos e institucionais, no entanto ela não será contemplada no artigo. Para os interessados, recomendamos, como leituras introdutórias, as obras de Almeida e Silva (2016) e Neri (2017). 
Aguiar (2012) destacou o efeito do Bolsa Família no empoderamento feminino via concessão do benefício para a mãe. Santos (2016) observou os benefícios do programa para a permanência das crianças na escola no município de Sinop, no Mato Grosso, e ressaltou a necessidade de maior participação das famílias na escolarização desses estudantes.

Os estudos supracitados evidenciam que os resultados do Programa Bolsa Família excedem a questão da transferência de renda e do enfrentamento da pobreza extrema, na medida em que o benefício incide no comportamento das famílias atendidas, induzindo, por meio das condicionalidades exigidas, a adoção de procedimentos que auxiliam na saúde e no desenvolvimento educacional das crianças.

Caracterizando-se como um programa de transferência condicionada de renda, seus beneficiários devem atender a duas condicionalidades interligadas. São elas:

- a realização de exames pré-natais, acompanhamento nutricional e vacinação das crianças;

- acompanhamento da frequência escolar dos beneficiários.

A identificação das famílias que necessitam do benefício e a verificação do cumprimento das condicionalidades ficam a cargo dos municípios, cabendo ao governo federal o repasse da verba fixada pelo Programa Bolsa Família.

No tocante às condicionalidades, salienta-se que a obrigatoriedade de frequência escolar tem a finalidade de romper com o ciclo intergeracional de pobreza, por meio da escolarização, porém sua eficácia tem sido questionada (Carnelossi e Bernardes, 2014), o que evidencia a importância de pesquisas que analisem os impactos do programa sobre a educação.

O Bolsa Família tem se caracterizado como objeto de estudo de diversos pesquisadores que, sob diferentes perspectivas, avaliaram a distribuição geográfica dos beneficiários, os critérios de seleção adotados pelo governo, o perfil dos beneficiários, o atendimento e o monitoramento das condicionalidades e os resultados do programa, entre outros fatores. $\mathrm{Na}$ condição de objeto de estudo relevante para a educação e para o enfrentamento das desigualdades sociais, o Programa Bolsa Família foi tema de teses, dissertações, ${ }^{2}$ artigos, livros e textos apresentados em eventos acadêmicos. No amplo conjunto de estudos produzidos ao longo dos anos de existência do programa, definimos como objetivos de estudo identificar e analisar a produção científica brasileira divulgada na base Scientific Electronic Library Online (SciELO) no período entre 2003 e 2018.

\section{MÉTODO}

Partindo da premissa de que as relações entre a educação e o Programa Bolsa Família apresentam elevada complexidade na medida em que envolvem múltiplos

2 Em pesquisa realizada no ano de 2014, Collares identificou 73 dissertações e 19 teses sobre o Bolsa Família (Collares, 2014, p. 29). Desse conjunto de 92 trabalhos, 37 procedem da área de ciências humanas, 44 das ciências sociais aplicadas e 11 da área da saúde. 
interesses e são mediadas por instituições localizadas em diferentes esferas do poder público, propomos abordar essas relações numa dupla perspectiva: de um lado, exploramos aspectos quantitativos procedentes da bibliografia consultada e, do outro, incorporamos aspectos qualitativos. $\mathrm{Na}$ concepção que orientou nosso percurso metodológico, a abordagem quantiqualitativa é a mais adequada para analisar o tema selecionado.

O ponto inicial do nosso estudo foi a definição do material de consulta. Considerando os diversos tipos de textos acadêmicos existentes, definimos os artigos científicos como objeto de análise. Concebemos os artigos de periódicos acadêmicos como produtos do saber científico tendo em vista que eles registram fragmentos de determinado campo da ciência, fomentam discussões teóricas e metodológicas e apresentam resultados - geralmente parciais - de pesquisas procedentes de diferentes áreas. Na condição de produtos do saber científico, os artigos também são espaço de divulgação da ciência e apresentam expressivo crescimento no decorrer das últimas décadas (Côrtes, 2006).

Para conhecer a produção científica existente a respeito do Programa Bolsa Família publicada em periódicos nacionais, elegemos como fonte para a pesquisa a base de dados SciELO. A opção justifica-se por se tratar de uma biblioteca eletrônica que reúne periódicos brasileiros criteriosamente selecionados. Nessa fonte, a busca foi realizada mediante a presença do descritor "Bolsa Família" nos títulos em associação ao radical "educ" em qualquer índice, tendo como recorte cronológico o período de 2003 a 2018.

A pertinência dos artigos em relação aos propósitos deste estudo foi verificada por meio da leitura dos títulos e resumos, tendo-se como critérios de inclusão a centralidade do Programa Bolsa Família e a apresentação de resultados referentes à educação. Isto é, os efeitos do programa sobre a área educacional deveriam ocupar o foco das discussões centrais da produção. Foram excluídos os ensaios teóricos, os relatos de experiências e os artigos sobre o extinto Programa Bolsa Escola.

Os artigos foram lidos integralmente e categorizados, considerando-se a temática investigada, os procedimentos metodológicos, o periódico de divulgação, o ano de publicação e a autoria, inicialmente registrados em uma planilha e tratados de maneira quantitativa. Nessa etapa, verificou-se o perfil dos autores na consulta de seus currículos na Plataforma Lattes, observando-se as variáveis: área de formação, titulação e instituição de pertencimento. A análise qualitativa do material levantado permitiu a aproximação entre os estudos discutidos a seguir. A categorização temática adotada fundamentou-se na análise de conteúdo de Bardin (2016), e, por conseguinte, durante a leitura dos estudos se buscou identificar elementos relevantes para o agrupamento dos conteúdos.

\section{RESULTADOS E DISCUSSÃO}

O levantamento realizado na base SciELO remeteu-nos 39 resultados. Posteriormente à análise dos títulos e resumos, em consonância com a aplicação dos critérios de exclusão e inclusão, localizamos 11 pesquisas que discutem o Programa 
Bolsa Família em relação à educação. As demais produções tinham como foco a saúde dos beneficiários (8), com destaque para questões nutricionais e mortalidade infantil; o programa enquanto política social de transferência de renda (8); ocupação e empregabilidade (5); questões de gênero (2); trabalho infantil (1); assistência social (1); administração pública (1); qualidade de vida (1); e violência doméstica (1). As pesquisas relacionadas à educação, objeto de estudo deste artigo, foram publicadas entre os anos de 2010 e 2018, conforme a Tabela 1.

Tabela 1 - Distribuição dos artigos segundo o ano de publicação.

\begin{tabular}{|l|c|c|c|c|c|c|c|}
\hline Ano & 2010 & 2013 & 2014 & 2015 & 2017 & 2018 & Total \\
\hline $\mathrm{f}$ & 1 & 4 & 1 & 1 & 3 & 1 & 11 \\
\hline
\end{tabular}

Fonte: Banco de dados da pesquisa.

Elaboração dos autores.

Observa-se que a produção de conhecimento sobre a relação entre o Programa Bolsa Família e a educação é baixa e descontínua, e o ano em que houve maior número de artigos publicados foi 2013. A divulgação dessas pesquisas ocorreu em periódicos de educação (4), economia (4), ciências sociais (2) e administração pública (1). O Quadro 1 apresenta uma síntese dos objetivos, métodos e resultados obtidos no que se refere à educação.

Quadro 1 - Sínteses das produções analisadas.

\begin{tabular}{|c|c|c|c|}
\hline Título/autores & Objetivo & Método & $\begin{array}{l}\text { Resultados } \\
\text { educacionais }\end{array}$ \\
\hline $\begin{array}{l}\text { "Uma avaliação } \\
\text { dos impactos } \\
\text { macroeconômicos e } \\
\text { sociais de programas } \\
\text { de transferência de } \\
\text { renda nos municípios } \\
\text { brasileiros". } \\
\text { Denes, Komatsu } \\
\text { e Menezes-Filho } \\
(2018)\end{array}$ & $\begin{array}{c}\text { Examinar as relações } \\
\text { entre dois programas } \\
\text { sociais, o Programa } \\
\text { Bolsa Família e o } \\
\text { Benefício de Prestação } \\
\text { Continuada, e } \\
\text { indicadores municipais } \\
\text { de atividade } \\
\text { econômica e educação. }\end{array}$ & $\begin{array}{c}\text { Correlação de } \\
\text { variáveis com } \\
\text { base em banco de } \\
\text { dados (indicadores } \\
\text { socioeconômicos, } \\
\text { Índice de } \\
\text { Desenvolvimento } \\
\text { da Educação Básica, } \\
\text { indicadores de } \\
\text { saúde). }\end{array}$ & $\begin{array}{l}\text { Apenas o Programa Bolsa } \\
\text { Família apresenta efeitos } \\
\text { sobre os indicadores de } \\
\text { educação, possivelmente via } \\
\text { condicionalidades. Há relação } \\
\text { entre o crescimento do Programa } \\
\text { Bolsa Família nos municípios e } \\
\text { o aumento na frequência escolar, } \\
\text { assim como decréscimo no atraso } \\
\text { escolar, porém nesses locais os } \\
\text { indicadores de qualidade da } \\
\text { educação menos cresceram. }\end{array}$ \\
\hline $\begin{array}{l}\text { "Política educacional, } \\
\text { pobreza e } \\
\text { educação: retrato } \\
\text { do atendimento } \\
\text { aos estudantes } \\
\text { beneficiários do } \\
\text { Programa Bolsa } \\
\text { Família no Paraná". } \\
\text { Silveira e Schneider } \\
\text { (2017) } \\
\end{array}$ & $\begin{array}{c}\text { Apresentar a } \\
\text { distribuiçãa } \\
\text { dos estudantes } \\
\text { beneficiários do } \\
\text { Programa Bolsa } \\
\text { Família no estado do } \\
\text { Paraná. }\end{array}$ & $\begin{array}{c}\text { Correlação de } \\
\text { variáveis com base } \\
\text { em banco de dados } \\
\text { (Sistema Presença e } \\
\text { censo escolar). }\end{array}$ & $\begin{array}{l}\text { As condições de oferta das } \\
\text { escolas em que estão as } \\
\text { crianças beneficiárias do } \\
\text { Programa Bolsa Família no } \\
\text { Paraná parecem reproduzir as } \\
\text { desigualdades sociais na medida } \\
\text { em que existem diferenças em } \\
\text { termos de qualificação docente } \\
\text { e infraestrutura, em detrimento } \\
\text { da população mais pobre. }\end{array}$ \\
\hline
\end{tabular}


Quadro 1-Continuação.

\begin{tabular}{|c|c|c|c|}
\hline Título/autores & Objetivo & Método & $\begin{array}{c}\text { Resultados } \\
\text { educacionais }\end{array}$ \\
\hline $\begin{array}{l}\text { "Contexto familiar } \\
\text { e cumprimento da } \\
\text { condicionalidade de } \\
\text { frequência escolar } \\
\text { no Programa Bolsa } \\
\text { Família no Ceará”. } \\
\text { Abreu e Aquino } \\
\text { (2017) }\end{array}$ & $\begin{array}{c}\text { Identificar as } \\
\text { características das } \\
\text { familias dos beneficiários } \\
\text { do Programa Bolsa } \\
\text { Família que exercem } \\
\text { influência significativa } \\
\text { sobre a probabilidade } \\
\text { de a condicionalidade } \\
\text { de frequência escolar ser } \\
\text { cumprida ou não. } \\
\end{array}$ & Entrevistas. & $\begin{array}{l}\text { O cumprimento ou não da } \\
\text { condicionalidade educacional } \\
\text { está relacionado ao engajamento } \\
\text { das mães dos beneficiários } \\
\text { nas atividades escolares dos } \\
\text { filhos, o que também depende } \\
\text { da escolaridade delas e do } \\
\text { interesse pelos estudos de seus } \\
\text { dependentes. }\end{array}$ \\
\hline $\begin{array}{l}\text { "Diferencial } \\
\text { educacional entre } \\
\text { beneficiários e não } \\
\text { beneficiários do } \\
\text { Programa Bolsa } \\
\text { Família". } \\
\text { Gonçalves, } \\
\text { Minicucci e Amaral } \\
\text { (2017) }\end{array}$ & $\begin{array}{c}\text { Observar possíveis } \\
\text { consequências da } \\
\text { condicionalidade } \\
\text { educacional para o } \\
\text { resultado escolar, } \\
\text { especialmente na } \\
\text { distorção idade-série } \\
\text { dos alunos beneficiários } \\
\text { do programa no censo } \\
\text { de } 2010 . \\
\end{array}$ & $\begin{array}{c}\text { Correlação de } \\
\text { variáveis com base } \\
\text { em banco de dados } \\
\text { (censo escolar). }\end{array}$ & $\begin{array}{c}\text { Foram encontradas } \\
\text { diferenças positivas entre } \\
\text { crianças beneficiadas pelo } \\
\text { Programa Bolsa Família e não } \\
\text { beneficiadas, principalmente } \\
\text { entre as de } 8 \text { a } 11 \text { anos, de } \\
\text { modo a evidenciar bons } \\
\text { resultados do programa na } \\
\text { manutenção das crianças na } \\
\text { escola. }\end{array}$ \\
\hline $\begin{array}{l}\text { "Programas sociais } \\
\text { no Brasil: um estudo } \\
\text { sobre o Programa } \\
\text { Bolsa Família no } \\
\text { interior do Nordeste } \\
\text { brasileiro". } \\
\text { Zimmermann e } \\
\text { Espínola (2015) } \\
\end{array}$ & $\begin{array}{l}\text { Estudar o Programa } \\
\text { Bolsa Família em } \\
\text { nível local, pautado } \\
\text { na percepção dos } \\
\text { beneficiários (saúde, } \\
\text { educação e assistência } \\
\text { social). }\end{array}$ & Questionários. & $\begin{array}{l}\text { Segundo a percepção dos } \\
\text { beneficiários, o programa } \\
\text { não teve grande impacto } \\
\text { sobre a frequência nem sobre } \\
\text { o rendimento escolar dos } \\
\text { estudantes. }\end{array}$ \\
\hline $\begin{array}{l}\text { "Uma análise do } \\
\text { efeito do Programa } \\
\text { Bolsa Família sobre } \\
\text { o desempenho } \\
\text { médio das escolas } \\
\text { brasileiras". } \\
\text { Camargo e Pazello } \\
\text { (2014) }\end{array}$ & $\begin{array}{l}\text { Avaliar o efeito de } \\
\text { aumento na proporção } \\
\text { de alunos beneficiados } \\
\text { pelo Programa Bolsa } \\
\text { Família nas escolas } \\
\text { sobre o desempenho } \\
\text { médio delas. }\end{array}$ & $\begin{array}{c}\text { Correlação de } \\
\text { variáveis com base } \\
\text { em banco de dados } \\
\text { (censo escolar, } \\
\text { acompanhamento } \\
\text { da frequência escolar } \\
\text { dos beneficiários } \\
\text { do Programa Bolsa } \\
\text { Família e Prova } \\
\text { Brasil). }\end{array}$ & $\begin{array}{l}\text { Verifica-se que o aumento } \\
\text { na proporção de alunos } \\
\text { beneficiados tende a reduzir } \\
\text { a taxa de abandono escolar, } \\
\text { contudo as evidências para a } \\
\text { taxa de aprovação e exames } \\
\text { de proficiência não foram } \\
\text { estatisticamente significativas. }\end{array}$ \\
\hline $\begin{array}{l}\text { "Análise da } \\
\text { contribuição do } \\
\text { Programa Bolsa } \\
\text { Família para o } \\
\text { enfrentamento } \\
\text { da pobreza e a } \\
\text { autonomia dos } \\
\text { sujeitos beneficiários". } \\
\text { Testa et al. (2013) }\end{array}$ & $\begin{array}{l}\text { Refletir sobre a } \\
\text { contribuição do } \\
\text { Programa Bolsa } \\
\text { Família para o } \\
\text { enfrentamento da } \\
\text { pobreza e maior } \\
\text { autonomia dos sujeitos } \\
\text { beneficiários. }\end{array}$ & $\begin{array}{l}\text { Questionários e } \\
\text { entrevistas. }\end{array}$ & $\begin{array}{c}\text { Sugere-se a melhora da } \\
\text { situação educacional dos } \\
\text { beneficiários após ingresso } \\
\text { no programa, sendo este } \\
\text { um dos aspectos que obteve } \\
\text { melhor resultado na busca } \\
\text { da autonomia. Não foram } \\
\text { encontrados relatos claros } \\
\text { sobre a aprendizagem. }\end{array}$ \\
\hline
\end{tabular}


Quadro 1-Continuação.

\begin{tabular}{|c|c|c|c|}
\hline Título/autores & Objetivo & Método & $\begin{array}{l}\text { Resultados } \\
\text { educacionais }\end{array}$ \\
\hline $\begin{array}{l}\text { "Avaliação de } \\
\text { impacto das } \\
\text { condicionalidades } \\
\text { de educação do } \\
\text { Programa Bolsa } \\
\text { Família (2005 e } \\
\text { 2009)". } \\
\text { Amaral e Monteiro } \\
\text { (2013) }\end{array}$ & $\begin{array}{c}\text { Verificar como } \\
\text { diferentes características } \\
\text { domiciliares, da mãe } \\
\text { e da criança, assim } \\
\text { como o recebimento } \\
\text { do Programa Bolsa } \\
\text { Família, explicam a } \\
\text { chance de crianças } \\
\text { abandonarem a escola } \\
\text { de um ano para o outro. }\end{array}$ & $\begin{array}{c}\text { Correlação de } \\
\text { variáveis com } \\
\text { base em banco de } \\
\text { dados (avaliação } \\
\text { de impacto do } \\
\text { Programa Bolsa } \\
\text { Família de } 2005 \text { e } \\
\text { 2009). }\end{array}$ & $\begin{array}{l}\text { Observou-se redução nas } \\
\text { chances de evasão escolar com } \\
\text { o recebimento do benefício } \\
\text { do Programa Bolsa Família, } \\
\text { estando a presença da mãe no } \\
\text { domicílio associada à menor } \\
\text { chance de evasão escolar. }\end{array}$ \\
\hline $\begin{array}{l}\text { "Afinal, para } \\
\text { que servem as } \\
\text { condicionalidades } \\
\text { em educação do } \\
\text { Programa Bolsa } \\
\text { Família?" } \\
\text { Pires (2013) }\end{array}$ & $\begin{array}{l}\text { Refletir sobre } \\
\text { estratégias de } \\
\text { enfrentamento da } \\
\text { pobreza com base } \\
\text { na exigência de } \\
\text { frequência escolar } \\
\text { mínima. }\end{array}$ & Entrevistas. & $\begin{array}{l}\text { As condicionalidades do } \\
\text { Programa Bolsa Família } \\
\text { podem ser compreendidas } \\
\text { como estabelecedoras de uma } \\
\text { relação recíproca entre os } \\
\text { beneficiários e o Estado. }\end{array}$ \\
\hline $\begin{array}{l}\text { "Programa Bolsa } \\
\text { Família e o } \\
\text { Nordeste: impactos } \\
\text { na renda e na } \\
\text { educação, nos anos } \\
\text { de } 2004 \text { e 2006". } \\
\text { Cavalcanti, Costa e } \\
\text { Silva (2013) }\end{array}$ & $\begin{array}{l}\text { Verificar o impacto } \\
\text { do Programa Bolsa } \\
\text { Família para as } \\
\text { famílias do Nordeste } \\
\text { brasileiro, o alívio } \\
\text { imediato da pobreza/ } \\
\text { desigualdade de renda } \\
\text { e a frequência escolar. }\end{array}$ & $\begin{array}{c}\text { Correlação de } \\
\text { variáveis com base } \\
\text { em banco de dados } \\
\text { (Pesquisa Nacional } \\
\text { por Amostra de } \\
\text { Domicílios). }\end{array}$ & $\begin{array}{l}\text { Foi verificado efeito positivo } \\
\text { na renda dos beneficiários, } \\
\text { porém menor que o impacto } \\
\text { exercido sobre a frequência } \\
\text { escolar. }\end{array}$ \\
\hline $\begin{array}{l}\text { "Impacto do } \\
\text { Programa Bolsa } \\
\text { Família sobre a } \\
\text { frequência escolar: o } \\
\text { caso da agricultura } \\
\text { familiar no Nordeste } \\
\text { do Brasil". } \\
\text { Melo e Duarte } \\
\text { (2010) }\end{array}$ & $\begin{array}{l}\text { Avaliar o impacto } \\
\text { do programa de } \\
\text { transferência de } \\
\text { renda condicionada } \\
\text { Bolsa Família sobre a } \\
\text { frequência escolar de } \\
\text { crianças e adolescentes } \\
\text { de } 5 \text { a } 14 \text { anos na } \\
\text { agricultura familiar } \\
\text { dos estados de } \\
\text { Pernambuco, Ceará, } \\
\text { Sergipe e Paraíba. }\end{array}$ & $\begin{array}{c}\text { Correlação de } \\
\text { variáveis com base } \\
\text { em banco de dados } \\
\text { (Pesquisa Nacional } \\
\text { por Amostra de } \\
\text { Domicílios). }\end{array}$ & $\begin{array}{l}\text { Constatou-se elevação da } \\
\text { frequência escolar das crianças } \\
\text { beneficiárias do programa, } \\
\text { porém existem diferenças } \\
\text { entre os gêneros, de maneira } \\
\text { que o programa demonstra } \\
\text { ser mais eficaz para o caso das } \\
\text { meninas que dos meninos. }\end{array}$ \\
\hline
\end{tabular}

Fonte: Banco de dados da pesquisa com base nos artigos disponíveis na Scientific Electronic Library Online. Elaboração dos autores.

Os estudos, em sua maioria, foram realizados por duplas (6), três em trios, um por quatro pesquisadores e um individualmente. De acordo com Giroto, Sabella e Lima (2019), a prática de produzir artigos em grupos com mais de três autores é bastante comum na área da saúde, o que não se estende para a da educação. $O$ mesmo parece aplicar-se às áreas de economia e ciências sociais, visto que a produção com mais de três autores foi divulgada em periódico de administração pública. Similar- 
mente, a publicação por um único autor também não é habitual, talvez pela grande incidência de pesquisas científicas realizadas no âmbito da pós-graduação, em que há um orientando e um orientador, o que explica o predomínio de publicações em duplas. No total de 25 autores, 17 são doutores e seis mestres, havendo dois que não foram localizados na Plataforma Lattes. ${ }^{3}$

A consulta na Plataforma Lattes possibilitou identificar, além da titulação, as áreas acadêmicas de atuação dos pesquisadores. Com base na titulação informada no currículo, o grupo de pesquisadores procede das seguintes áreas e subáreas acadêmicas: economia (7), sociologia (5), educação (2), serviço social (2), administração (2), ciências sociais (1), gestão pública (1), ciência política (1), teoria econômica (1) e ciências econômicas (1).

Quando observamos a área de formação dos pesquisadores, a expressiva participação de autores procedentes da economia e da sociologia é facilmente constatada. Eles correspondem a $50 \%$ da amostra. A porcentagem atinge $64,4 \%$ se incluirmos no grupo dos sociólogos e economistas os dois pesquisadores da área do serviço social, os dois procedentes da administração e os dois pesquisadores que possuem mestrado em áreas correlacionadas à economia (teoria econômica e ciências econômicas). No sentido oposto, a presença de pesquisadores procedentes da educação é baixa, havendo apenas dois autores com formação na área.

Os vínculos institucionais dos autores indicam predomínio de universidades públicas (7), seguido de instituições de ensino privadas (3) e de outras instituições (3). ${ }^{4}$ Os dados permitem-nos constatar que as pesquisas sobre o Programa Bolsa Família estão descentralizadas, pois não houve repetição de instituições na amostra coletada. Cabe ressaltar o papel relevante das universidades públicas como produtoras de reflexão crítica a respeito dos objetivos, do funcionamento e dos resultados do programa.

Das pesquisas recuperadas, sete ocorreram mediante a análise quantitativa de um ou mais banco de dados, como o censo demográfico, o censo escolar, o Índice de Desenvolvimento da Educação Básica (IDEB), a Prova Brasil, o Sistema Presença e a Pesquisa Nacional por Amostra de Domicílios (PNAD), enquanto as quatro investigações restantes foram realizadas por meio de questionários e/ou entrevistas.

\section{PARA ALÉM DOS NÚMEROS: LEITURAS SOBRE O PROGRAMA BOLSA FAMÍLIA NA BASE DE DADOS DA SCIELO}

Identificamos cinco categorias com base na análise qualitativa do conteúdo dos artigos. São elas:

1. condicionalidade de educação;

2. concepções sobre o Programa Bolsa Família;

3 Durante a elaboração do estudo, tentamos contatar o autor pelo $e$-mail indicado em seu artigo, mas não recebemos retorno.

4 Aquelas que não se enquadram como instituições de ensino superior são o Instituto Nacional do Seguro Social (INSS), a Secretaria de Educação do Estado da Bahia e a Secretaria de Estado do Planejamento e das Finanças do Rio Grande do Norte. 
3. indicadores educacionais;

4. distorção idade-série;

5. condições de oferta escolar.

A seguir, apresentamos os principais resultados dessas pesquisas.

\section{CONDICIONALIDADE DE EDUCAÇÃO}

Foram quatro os trabalhos que se dedicaram a analisar o impacto do Programa Bolsa Família sobre a frequência escolar e/ou quais são as características familiares que influenciam o cumprimento dessa condicionalidade educacional.

Melo e Duarte (2010) avaliaram o impacto do Bolsa Família na frequência escolar de crianças e adolescentes da agricultura familiar dos estados de Pernambuco, Ceará, Paraíba e Sergipe em 2005. Os autores utilizaram dados do Projeto Dom Helder Câmara, da Universidade Federal de Pernambuco, e da PNAD, constituindo uma amostra de 1.120 pessoas em idade escolar, as quais compunham três grupos: beneficiários do Programa Bolsa Família pertencentes a domicílios rurais (grupo de tratamento); domiciliados na zona rural, sem participação no Programa Bolsa Família (grupo controle 1); e não beneficiários de qualquer programa de transferência de renda, mas que o chefe da família desempenhe atividade laboral agrícola no meio rural (grupo controle 2). A comparação entre grupos revelou que o grupo de tratamento apresenta maior frequência escolar $(98,1 \%)$ que os grupos controle 1 $(80,3 \%)$ e 2 (87,4\%). Entretanto, ao considerar as diferenças de gênero, analisando separadamente os dados de meninas e meninos, obteve-se a indicação de impactos significativos e positivos do programa sobre a frequência daquelas, o que não se observou entre os meninos, cujas diferenças não possuem significância estatística. Tal resultado foi interpretado como um reflexo da importância do jovem do gênero masculino para o trabalho agrícola no meio rural.

Cavalcanti, Costa e Silva (2013) verificaram o impacto do Programa Bolsa Família no alívio imediato da pobreza e frequência escolar para famílias da Região Nordeste, áreas urbana e rural, utilizando dados da PNAD de 2004 a 2006. Foram selecionados dois grupos de famílias: as beneficiadas pelo programa (grupo de tratamento) e as elegíveis, mas não beneficiadas (grupo de comparação). Os resultados mostraram que há impacto positivo do programa sobre a renda das famílias, principalmente para as que enfrentam a pobreza extrema, mas a magnitude de tal efeito é baixa, indicando impacto mínimo. No que se refere à frequência escolar, esta apresenta impacto de magnitude mais elevada, e a frequência é maior entre os beneficiados do Programa Bolsa Família em comparação aos não beneficiados, porém a taxa de aprovação inverte-se entre esses grupos, e as crianças atendidas pelo programa apresentam maior participação laboral. Em 2004, eram 72.087 crianças beneficiadas que trabalhavam contra 39.430 entre as não beneficiadas, passando para 86.824 e 34.215 em 2006, respectivamente.

Com o intuito de verificar se o recebimento do benefício do Programa Bolsa Família e as variáveis relativas ao domicílio, à mãe e à criança exercem efeitos sobre a evasão escolar, Amaral e Monteiro (2013) consultaram e analisaram o banco de 
dados referente à Avaliação de Impacto do Programa Bolsa Família (AIBF), do Ministério do Desenvolvimento Social e Combate à Fome (MDS), de 2005 e 2009. Foram considerados três grupos: famílias beneficiárias do Programa Bolsa Família; famílias não beneficiárias, mas incluídas no Cadastro Único; e famílias não incluídas no Cadastro Único, mas com condições semelhantes às de famílias cadastradas. Da comparação entre grupos e intragrupos (considerando três faixas de renda), os autores concluíram que a participação no Programa Bolsa Família diminui as chances de abandono escolar, efeito potencializado pela presença da mãe da criança no domicílio, principalmente nos casos em que elas participam de organizações sociais/comunitárias.

Abreu e Aquino (2017) conduziram um estudo envolvendo 341 participantes do estado do Ceará com vistas a identificar características familiares que influenciam no cumprimento da condicionalidade de frequência escolar. A amostra contemplou 180 familias que cumprem a condicionalidade e 160 que não a cumprem. Valendo-se de entrevistas semiestruturadas com a colaboração dos alunos do curso de especialização Educação, Pobreza e Desigualdade Social, as quais foram convertidas em respostas fechadas em formato de formulário, para viabilizar análises estatísticas, os autores encontraram diferença significativa entre as mães que possuem um companheiro e as que não o possuem, e o percentual de cumprimento da condicionalidade é maior entre as famílias em que a mulher vive em situação marital. A conformidade da frequência exigida tende a ser favorecida na medida em que há menor número de filhos e a mãe apresenta bom conhecimento do universo escolar - conhece o(a) diretor(a) e as atividades extracurriculares desenvolvidas. Mais do que saber quem é a professora do(a) filho(a), a ciência sobre aspectos administrativos e pedagógicos indica o estabelecimento de contato direto com a escola. A taxa de descumprimento também decresce com a prestação de auxílio, seja pela mãe, seja por outro familiar, nas tarefas escolares.

\section{CONCEPÇÕES SOBRE O PROGRAMA BOLSA FAMÍLIA}

Os três estudos pertencentes a esta categoria refletem sobre as contribuições do Programa Bolsa Família para a educação (entre outras áreas) com base nas percepções dos próprios beneficiários.

Pires (2013) entrevistou 22 beneficiários do Programa Bolsa Família da cidade de Campinas (SP) com o intuito de compreender a percepção desses indivíduos sobre tal política de transferência de renda condicionada. Segundo o autor, as falas dos entrevistados revelaram a concepção de que a participação no programa representa uma espécie de celebração de contrato, no qual existe um compromisso entre a família e o Estado, sendo o cumprimento da frequência escolar uma contrapartida. Essa relação de troca e reciprocidade é entendida por Pires (2013) como promotora de benefícios que vão além daqueles propiciados pela própria escolarização das crianças e adolescentes, pois se trata de atribuir reconhecimento social a essas famílias de modo a fortalecer o sentimento de pertencimento.

Testa et al. (2013) tiveram como objetivo refletir sobre a relação entre o Programa Bolsa Família, o enfrentamento da pobreza e a autonomia dos beneficiários. Para isso, 103 famílias beneficiadas pelo programa em Porto Alegre responderam 
a um questionário. A pesquisa também envolveu entrevistas com três profissionais de Centros de Referência de Assistência Social (CRAS) e com quatro famílias atendidas nesses CRAS. Os resultados apontam efeitos do programa sobre a escolarização dos estudantes beneficiários, visto que $76,7 \%$ das famílias que responderam ao questionário consideram que houve melhora na situação educacional dos estudantes após a implantação do benefício. As profissionais dos centros percebem que há maior cuidado por parte das famílias no que tange à frequência escolar das crianças e jovens, o que gera a expectativa de diminuição da evasão escolar. As entrevistas com as famílias confirmaram essas percepções, porém salienta-se que os relatos não expressaram melhorias na aprendizagem. Com base nos enunciados das profissionais, os autores compreendem que, além das variáveis culturais e contextuais, a não observação de resultados referentes ao desempenho pode estar relacionada à baixa qualidade das escolas que se localizam nas regiões pesquisadas, eleitas por seus níveis de vulnerabilidade social. Conclui-se, ainda, que a exigência pela frequência nas aulas surge como uma obrigação determinada pelo programa, mas que progressivamente se torna fruto da valorização da escola na medida em que as famílias percebem reflexos positivos da escolarização e desejam que seus filhos continuem os estudos, o que evidencia aumento na autonomia, associado ao crescimento da capacidade dos responsáveis de proporcionar educação aos filhos com vistas a experienciarem melhores condições de vida.

Zimmermann e Espínola (2015) conduziram uma investigação no município de São Felipe, na Bahia, com o intuito de conhecer as percepções das beneficiárias sobre o programa. Os dados foram coletados por meio de survey e contou com a participação de 344 indivíduos, das quais 178 eram residentes da zona rural. No que se refere às percepções sobre o impacto do Programa Bolsa Família na educação, o tamanho dos efeitos percebidos é pequeno, pois $73,28 \%$ das beneficiárias consideram que a frequência escolar dos filhos não se alterou após a implantação do benefício, ao passo que 56,49\% acreditam que o rendimento escolar permaneceu o mesmo. Em contrapartida, 32,93\% das participantes perceberam melhora no rendimento escolar das crianças. Os autores concluem que o principal problema da educação em São Felipe se encontra na qualidade, mas o programa só intervém no acesso à escola. Em análise a proposições de transferência da condicionalidade de frequência para o acompanhamento do rendimento, argumentam que, nesse caso, o foco deve deslocar-se do indivíduo para o Estado, responsável por proporcionar ensino de qualidade para todos.

\section{INDICADORES EDUCACIONAIS}

Dois estudos examinaram a relação entre o Programa Bolsa Família e indicadores educacionais, como o IDEB e a Prova Brasil.

Camargo e Pazello (2014) avaliaram a incidência de efeito do aumento de beneficiários sobre o desempenho médio das escolas com base nos dados do censo escolar, da Prova Brasil e do Cadastro de Acompanhamento da Frequência Escolar dos Beneficiários do Programa Bolsa Família, considerando-se os alunos que estavam na $4^{a}$ série em 2009 e envolvendo procedimento de estimação. As escolas foram divididas pelo percentual de beneficiários: menos de 25\%; entre 25\% e 50\%; entre 50\% e 75\%; 
e acima de $75 \%$. Inicialmente, os resultados indicaram que, quanto maior a proporção de beneficiários, menor a proficiência dos estudantes em português e matemática. As escolas com mais beneficiários também tendem a apresentar menor taxa de aprovação e maior taxa de evasão escolar; são menores, com infraestrutura inadequada; e mães com menor grau de escolaridade e maior probabilidade de localizar-se na zona rural. Contudo, a estimativa de efeito do aumento de beneficiários em uma escola sugere somente a diminuição nas taxas de abandono, sem confirmar a redução das aprovações, e o mesmo é válido para a proficiência dos estudantes, pois os testes de robustez evidenciaram que tais escolas já vinham apresentando resultados inferiores desde anteriormente à criação do Programa Bolsa Família, de maneira a configurar a necessidade de maior atenção por parte do poder público.

Denes, Komatsu e Menezes-Filho (2018) analisaram os efeitos do Programa Bolsa Família e do Benefício de Prestação Continuada sobre indicadores municipais, com base em estimativas com efeitos fixos de municípios e tendências estaduais controlados, abrangendo o período de 2004 a 2010. Os impactos sobre a educação, especificamente, foram avaliados haja vista a frequência escolar, a defasagem idade-série, o IDEB e a Prova Brasil. Os autores verificaram que, entre os anos de 2004 a 2010, houve crescimento geral nos municípios em relação à frequência escolar, com destaque para o ensino médio, tal qual a redução na defasagem idade-série. Também foi observado aumento na média das notas e do IDEB na $4^{\text {a }}$ e na $8^{\text {a }}$ série do ensino fundamental. Ao realizarem estimativas sobre os dois programas de transferência de renda, controlando ainda os repasses do Fundo de Participação dos Municípios e outras transferências do governo federal, foram confirmados os efeitos do Programa Bolsa Família sobre a frequência e a redução da defasagem idade-série, porém com efeito negativo sobre as notas e o IDEB. Os autores argumentam que o Programa Bolsa Família mantém na escola crianças e jovens que não estariam lá na inexistência do programa e, caso esses estudantes apresentem baixo desempenho, se tende a ter queda nas médias de notas das escolas, repercutindo nos indicadores de qualidade. Não foram encontrados resultados significativos em relação ao Benefício de Prestação Continuada e indicadores de qualidade, havendo efeito negativo quanto à frequência, uma vez que não há a condicionalidade educacional. Já as transferências do Fundo de Participação dos Municípios produziram efeitos positivos sobre todos os indicadores educacionais analisados, revelando o impacto dos repasses na qualidade da educação.

\section{DISTORÇÃO IDADE-SÉRIE}

Esta categoria aloca um único estudo que se dedica a analisar as consequências do Programa Bolsa Família na distorção idade-série, isto é, a frequência em turma escolar diferente da adequada para a idade.

Gonçalves, Minicucci e Amaral (2017) abordaram o problema da distorção idade-série com base nos dados do censo demográfico de 2010 e concluíram que as crianças residentes em domicílios beneficiados pelo Programa Bolsa Família apresentam índice de distorção idade-série menor do que as crianças não atendidas pelo programa. 
Sem desconsiderar a existência de outros fatores que incidem na distorção idade-série, como, por exemplo, a composição mais homogênea ou mais heterogênea do público escolar, o background familiar, a infraestrutura das escolas e o trabalho docente, os autores concentraram suas atenções na comparação da distorção idade-série entre beneficiários e não beneficiários usando a regressão logística binária controlada por efeito fixo e criaram modelos para delimitar a comparação. Os resultados obtidos, baseados no cruzamento de variáveis como a renda per capta, ${ }^{5}$ a idade das crianças e a escolaridade das mães, confirmaram a hipótese de que crianças beneficiadas pelo Programa Bolsa Família apresentavam menor distorção idade-série. Eles também apontaram outros aspectos relevantes para a compreensão do fenômeno da distorção idade-série, entre os quais destacamos:

- a maior probabilidade de a distorção ocorrer entre os meninos foi constatada em todos os seis modelos elaborados;

- o problema é mais acentuado no grupo de crianças com faixa etária entre 10 e 14 anos;

- a diferença observada na distorção idade-série entre crianças da zona rural e crianças da zona urbana foi pequena;

- o grupo de crianças de 14 anos da zona urbana apresenta maior ocorrência de distorção idade-série.

\section{CONDIÇÕES DE OFERTA ESCOLAR}

Com apenas uma pesquisa, esta categoria refere-se à investigação das condições educacionais que são oferecidas aos estudantes que vivem em situação de pobreza.

Silveira e Schneider (2017), autores do artigo contemplado nesta categoria, abordaram o tema com base na realidade do Paraná e analisaram fatores como as condições de trabalho docente (contrato de trabalho e formação) e as condições de infraestrutura da escola (biblioteca, internet, banda larga, laboratório de informática e quadra de esporte). Os dados apresentados pelos autores foram retirados do Banco do Sistema Presença de 2014 e do censo escolar do respectivo ano.

Os autores constataram que, no estado do Paraná, o programa atingiu o destino previsto, apresentando maior concentração em municípios com baixo índice de desenvolvimento humano (IDH). No ano de 2014, quando os dados foram coletados, cerca de $20 \%$ dos estudantes do ensino fundamental que frequentavam as escolas do Paraná eram beneficiados pelo programa - um número abaixo da média nacional, que apontava cerca de $40 \%$.

5 A classificação por renda per capita adotada no artigo fixou a divisão dos beneficiários do Programa Bolsa Família em dois subgrupos: crianças cuja renda domiciliar per capita é até $\mathrm{R} \$ 70$ (valor que coincide com as famílias em extrema pobreza); e até $\mathrm{R} \$ 140$. Cabe a ressalva de que os autores consideraram a família como unidade beneficiada, e não somente a criança. Com essa interpretação, todas as crianças de um domicílio onde ocorreu a autodeclaração do benefício no censo de 2010 foram classificadas como beneficiárias (Gonçalves, Minicucci e Amaral, 2017, p. 782). 
Para avaliar as condições de oferta escolar — aspecto que remete ao conceito mais amplo de qualidade na educação, Silveira e Schneider (2017) organizaram as escolas paranaenses em quatro faixas definidas pelo percentual de estudantes beneficiários do Programa Bolsa Família. Na classificação usada pelos autores, suprimiu-se a distinção entre escolas estaduais e municipais e adotou-se a seguinte divisão: "Baixa presença de beneficiários de até $11 \%$ de bolsistas; média-baixa de $11 \%$ a $18 \%$; média de $18 \%$ a 27\%; e, alta, quando havia mais de $27 \%$ de bolsistas" (Silveira e Schneider, 2017, p. 120). Posteriormente, analisaram a formação dos docentes e o tipo de vínculo profissional que possuíam. Nesse item, constataram que a porcentagem de professores contratados temporariamente é maior nas escolas com alta concentração de beneficiários do Programa Bolsa Família. A pesquisa também permitiu observar expressiva diferença entre o número de docentes contratados na rede estadual (52\%) e a quantidade contratada no conjunto das redes municipais (33,3\%).

Analisando a formação dos docentes que atuam na educação básica no Paraná, os autores identificaram correlação negativa entre o número de beneficiários e a formação docente, e as escolas com maior percentual de beneficiários possuem os professores com menor qualificação. Nessas instituições, localiza-se o maior número de professores sem a formação mínima exigida, especialmente nas séries iniciais, e o mesmo ocorre com a formação na modalidade normal em nível médio.

Os autores ressaltam ainda diferenças na infraestrutura das escolas segundo o percentual de beneficiários, sobretudo nas escolas municipais onde a precariedade das condições materiais acompanha o crescimento da população em condições de pobreza.

\section{PROGRAMA BOLSA FAMÍLIA E A EDUCAÇÃO: UMA DISCUSSÃO IMPRESCINDÍVEL}

O Programa Bolsa Família tem sido responsável por resultados significativos em termos de redução da pobreza e extrema pobreza no país (Amaral e Monteiro, 2013; Cavalcanti, Costa e Silva, 2013), mas seus objetivos superam o alívio imediato das circunstâncias impostas pela insuficiência de renda, pois visam à emancipação de seus beneficiários.

Arruda (2017) desenvolveu um estudo com o objetivo de conhecer a percepção de mães beneficiadas no estado de São Paulo sobre o Programa Bolsa Família em suas condições de vida. As participantes revelaram perceber o auxílio como um complemento de renda temporário que favorece as condições de sobrevivência, uma vez que o destino principal do recurso financeiro é a alimentação. Entretanto, evidencia-se a dificuldade de inserção dessas mulheres no mercado de trabalho formal, principalmente por sua baixa escolaridade. Elas concebem qualidade de vida como a possibilidade de satisfação das necessidades básicas de subsistência, sobretudo alimentação e moradia, aspectos nos quais depositam seus sonhos e expectativas. Tais resultados ilustram a relevância da condicionalidade de educação na concessão do benefício tendo-se como propósito o fim da reprodução das situações de pobreza entre as gerações. Logo, investigar os efeitos dessa condicionalidade na escolarização dos estudantes beneficiários do Programa Bolsa Família torna-se imprescindível. 
Sem desconsiderar os limites de nossa amostra, podemos afirmar que existe, na base de dados da SciELO, produção acadêmica consistente sobre o funcionamento do Programa Bolsa Família. Nela, observamos que o interesse dos pesquisadores em relação à educação contempla três eixos temáticos interligados. O primeiro diz respeito à discussão sobre a eficiência (ou ineficiência) da condicionalidade de frequência escolar; o segundo explora o impacto do Programa Bolsa Família no desempenho dos estudantes, sendo este mensurado por indicadores como reprovação e avaliações externas; e o terceiro eixo, quantitativamente menos expressivo, explora a percepção dos agentes sociais envolvidos, sobretudo as famílias e os estudantes diretamente beneficiados pelo programa.

De maneira sintética, as pesquisas revelam que a condicionalidade de educação imposta pelo Programa Bolsa Família promove aumento da frequência escolar dos estudantes beneficiários (Cavalcanti, Costa e Silva, 2013; Melo e Duarte, 2010) e diminui a defasagem idade-série (Denes, Komatsu e Menezes-Filho, 2018; Gonçalves, Minicucci e Amaral, 2017) e as chances de evasão escolar (Amaral e Monteiro, 2013).

$\mathrm{O}$ ato de atender a tal condicionalidade é compreendido pelas famílias beneficiárias como uma contrapartida na celebração de um acordo com o Estado, o que lhes proporciona o sentimento de reconhecimento social e maior autonomia, uma vez que podem oferecer educação escolar aos filhos (Pires, 2013; Testa et al., 2013). Nessa perspectiva, existem condições que contribuem para o atendimento da exigência, de modo que a taxa de cumprimento dessa condicionalidade é maior nos domicílios em que a mãe possui um companheiro, o número de filhos não é elevado e há participação dos responsáveis na vida escolar das crianças e adolescentes (Abreu e Aquino, 2017).

Para além da frequência escolar, é relevante pensarmos a complexidade das relações entre o Programa Bolsa Família e o desempenho escolar das crianças beneficiadas. Acredita-se que essas relações demandam maior atenção dos pesquisadores e, sobretudo, do Estado, pois as condições econômicas e os recursos humanos que os municípios possuem influenciam no desempenho escolar de crianças beneficiadas e não beneficiadas, como destacado por Denes, Komatsu e Menezes-Filho (2018) ao constatarem que o repasse de recursos financeiros aos municípios influencia a qualidade da educação.

No que se refere à relação entre o Programa Bolsa Família e o desempenho acadêmico, não foram encontrados efeitos da transferência de renda condicionada sobre a aprendizagem dos estudantes (Testa et al., 2013; Zimmermann e Espínola, 2015). Ainda, escolas com maior número de beneficiários apresentam piores resultados nos desempenhos em português e matemática medidos por avaliações externas, além de taxas mais elevadas de reprovação. Em síntese, a incidência de resultados negativos (já existentes antes do Programa Bolsa Família) revela o descaso do poder público com as escolas localizadas nas áreas mais pobres, as quais, geralmente, tendem a apresentar infraestrutura precária, professores menos qualificados e que atuam com contratos temporários (Camargo e Pazello, 2014; Silveira e Schneider, 2017). Mais do que uma simples distinção entre categorias de vínculo profissional (concursados ou contratados temporariamente), os dados remetem ao problema da precarização da docência e, consequentemente, dificultam o objetivo do enfrentamento da pobreza pelo viés da educação escolar - objetivo que está na gênese do Programa Bolsa Família. 
Nesse sentido, Carnelossi e Bernardes (2014) argumentam que o programa propicia formação insuficiente e, consequentemente, produz mão de obra desqualificada e pouco contribui para a resolução do problema estrutural que é a pobreza.

Adicionalmente, os achados das pesquisas também apontaram para diferenças de gênero no que tange aos impactos do programa, de maneira que as meninas tendem a apresentar mais presença na escola que os meninos, sendo estes os que apresentam maior distorção idade-série (Gonçalves, Minicucci e Amaral, 2017; Melo e Duarte, 2010). Infere-se que essa diferença possa estar relacionada à inserção dos meninos no mercado informal de trabalho. Logo, Cavalcanti, Costa e Silva (2013) recomendam tanto a ampliação do valor do benefício quanto do número de beneficiados a fim de aumentar o impacto sobre a renda familiar e a frequência escolar de jovens e crianças, esta última considerada a principal justificativa para o programa por colaborar com o crescimento do capital humano e o rompimento do ciclo intergeracional da pobreza. Entretanto, se o objetivo da condicionalidade de educação é o rompimento do referido ciclo, para além da frequência, é necessário discutir sobre a qualidade da educação oferecida pelos sistemas públicos de ensino, já que esta desempenha papel crucial no desenvolvimento humano (Pires, 2013; Vygotsky, 1981).

Ao discutirem a relação entre educação e pobreza, Yannoulas, Assis e Ferreira (2012) advertem que medidas referentes à garantia de alimentação, uniforme, material escolar e outras, muitas vezes tidas como assistencialistas, não existem porque a escola pública recebe crianças consideradas carentes. Similarmente, as ações e os programas para a melhoria do desempenho escolar não são necessários para que se preencham lacunas resultantes de déficits causados pela escassez de recursos materiais/culturais. As referidas concessões nada mais são que o respeito a direitos legalmente assegurados tanto na Constituição Federal como na Lei de Diretrizes e Bases da Educação Nacional e no Estatuto da Criança e do Adolescente. Nesse prisma, os autores salientam que a expansão quantitativa da escolaridade não é capaz de promover, por si só, a ampliação da justiça social. A permanência das crianças e adolescentes de contextos empobrecidos na escola deve estar acompanhada por aspectos qualitativos que levem em conta as implicações de ordem econômica, política, cultural e educacional envolvidas no processo de escolarização, a fim de propiciar as condições fundamentais ao exercício da cidadania.

\section{CONSIDERAÇÕES FINAIS}

O Programa Bolsa Família destina-se à transferência condicionada de renda com o intuito não somente de combater a fome e a miséria que assolam o país, mas proporcionar condições para o rompimento do ciclo intergeracional de pobreza, $o$ que atribui à educação papel de destaque. Tendo como objetivos identificar e analisar a produção científica nacional disponível na base SciELO que investiga a relação entre o Programa Bolsa Família e a educação, localizamos 11 artigos científicos.

A leitura dos dados referentes à formação dos autores apontou um aspecto interessante e que pode ser explorado em novos estudos. Constatamos o predomínio de profissionais que não possuem formação acadêmica em educação, e apenas dois dos 23 autores localizados na Plataforma Lattes possuem doutorado nessa 
área. Acreditamos que o perfil dos pesquisadores pode explicar, em parte, a ênfase nos aspectos quantitativos observada no conjunto dos artigos analisados. A priori, pesquisadores da área da economia, da sociologia e da administração possuem maior familiaridade com estudos quantitativos e tendem a interpretar os fenômenos sociais baseados em variáveis numéricas, e, mesmo quando abordam temas diretamente associados à educação, como é o caso do Programa Bolsa Família, economistas, sociólogos e administradores tendem a privilegiar fatores econômicos e políticos que influenciam, direta ou indiretamente, na educação escolar.

Em linhas gerais, os estudos apontam para a eficácia do programa na manutenção das crianças e adolescentes na escola, porém pouco se sabe sobre a qualidade da aprendizagem atingida por esses estudantes. Se por um lado se verifica que as escolas com maior número de beneficiários demonstram menor índice de desempenho estudantil em avaliações externas, por outro se observa que tais escolas se localizam nos contextos mais empobrecidos e são as que menos recebem investimentos por parte do poder público no que tange à condição de oferta educacional, o que inclui desde infraestrutura à qualificação do corpo docente. A relevância social da temática exige a realização de novos estudos.

Diante do que foi exposto, estamos convictos de que existe a necessidade da produção de pesquisas que analisem a relação entre o Programa Bolsa Família e a educação haja vista aspectos qualitativos, que considerem experiências e subjetividades, bem como permitam uma compreensão mais aprofundada dessa relação. Nesse sentido, enfatizamos a importância da discussão sobre a qualidade do ensino escolar oferecido para os beneficiários do programa enquanto estratégia de superação do ciclo intergeracional de pobreza.

\section{REFERÊNCIAS}

ABREU, D.; AQUINO, J. A. Contexto familiar e cumprimento da condicionalidade de frequência escolar no Programa Bolsa Família no Ceará. Educar em Revista, Curitiba, edição especial, n. 2, p. 55-69, set. 2017. Disponível em: http://www.scielo.br/scielo. php?pid=S0104-40602017000600055\&script=sci_abstract\&tlng=pt. Acesso em: 12 jan. 2019. http://dx.doi.org/10.1590/0104-4060.52955

AGUIAR, N. F. Diferenças de gênero e apoio à pobreza no Programa Bolsa Família (PBF). Brasília, DF: Secretaria de Avaliação e Gestão da Informação, Ministério do Desenvolvimento Social e Combate à Fome, 2012.

ALMEIDA, M. L.; SILVA, J. L. G. Os programas de transferência de renda no Brasil e sua relação com a melhoria da qualidade de vida da população pobre e extremamente pobre: um estudo sobre o Bolsa Família. G\&DR, Taubaté, v. 12, n. 3, p. 60-80, set./ dez. 2016. Disponível em: https://www.rbgdr.net/revista/index.php/rbgdr/article/ download/2513/534. Acesso em: 7 jan. 2019.

AMARAL, E. F. L.; MONTEIRO, V.P. Avaliação de impacto das condicionalidades de educação do Programa Bolsa Família (2005 e 2009). DADOS - Revista de Ciências Sociais, Rio de Janeiro, v. 56, n. 3, p. 531-570, 2013. Disponível em: http://www.scielo. br/scielo.php?pid=S0011-52582013000300003\&script=sci_abstract\&tlng=pt. Acesso em: 10 fev. 2019. http://dx.doi.org/10.1590/S0011-52582013000300003 
ARRUDA, P. A. Programa Bolsa Família sobre o olhar dos beneficiários de um município do interior de São Paulo. 2017. Dissertação (Mestrado em Saúde, Interdisciplinaridade e Reabilitação) - Faculdade de Ciências Médicas, Universidade Estadual de Campinas, Campinas, 2017.

BARDIN, L. Análise de conteúdo. Tradução Luís Antero Reto e Augusto Pinheiro. São Paulo: Edições 70, 2016.

BARRIENTOS, A.; DEBOWICZ, D.; WOOLARD, I. Heterogeneity in Bolsa Família outcomes. The Quarterly Review of Economics and Finance, Champaign, IL, n. 62, p. 33-40, 2016. Disponível em: https://www.sciencedirect.com/science/ article/pii/S1062976916300552. Acesso em: 7 out. 2019. https://doi.org/10.1016/j. qref.2016.07.008

BRASIL. Constituição da República Federativa do Brasil. Brasília, DF: Senado Federal; Centro Gráfico, 1988.

BRASIL. Lei n. 10.836, de 9 de janeiro de 2004. Cria o Programa Bolsa Família e dá outras providências. Diário Oficial da União, Brasília, DF, 12 jan. 2004. Disponível em: http://www.planalto.gov.br/ccivil_03/_Ato2004-2006/2004/Lei/L10.836.htm. Acesso em: 19 mar. 2019.

BRASIL. Decreto n. 5.209, de 17 de setembro de 2004. Regulamenta a lei n. 10.836, de 9 de janeiro de 2004, que cria o Programa Bolsa Família, e dá outras providências. Diário Oficial da União, 20 set. 2004. Disponível em: http://www.planalto.gov.br/ ccivil_03/_Ato2004-2006/2004/Decreto/D5209.htm. Acesso em: 19 jan. 2019.

CAMARGO, P.C.; PAZELLO, E.T.Uma análise do efeito do Programa Bolsa Família sobre o desempenho médio das escolas brasileiras. Economia Aplicada, Ribeirão Preto, v. 18, n. 4, p. 623-640, 2014. Disponível em: www.scielo.br/scielo.php?script=sci_ar ttext\&pid=S1413-80502014000400003. Acesso em: 21 jan. 2019. http://dx.doi. org/10.1590/1413-8050/ea388

CARNELOSSI, B. C. N.; BERNARDES, M.E. M. A condicionalidade de educação dos programas de transferência de renda: uma análise crítica do programa Bolsa Família. Perspectiva, Florianópolis, v. 32, n. 1, p. 285-313, jan./abr. 2014. Disponível em: https:// periodicos.ufsc.br/index.php/perspectiva/article/view/2175-795X.2014v32n1p285. Acesso em: 5 jan. 2019. https://doi.org/10.5007/2175-795X.2014v32n1p285

CAVALCANTI, D. M.; COSTA, E. M.; SILVA, J. L. M. Programa Bolsa Família e o Nordeste: impactos na renda e na educação, nos anos de 2004 e 2006. Revista de Economia Contemporânea, Rio de Janeiro, v. 17, n.1,p. 99-128, jan./abr.2013. Disponível em: http:// www.scielo.br/scielo.php?pid=S1415-98482013000100004\&script=sci_abstract\&tlng=pt. Acesso em: 17 jan. 2019. http://dx.doi.org/10.1590/S1415-98482013000100004

COLLARES, M. E. H. Combate à pobreza: a educação e o Programa Bolsa Família. 2014. Tese (Doutorado em Educação) — Programa de Pós-Graduação em Educação, Universidade Estadual de Campinas, Campinas, 2014.

CÔRTES, P. L. Considerações sobre a evolução da ciência e da comunicação científica. In: POBLACION, D. A.; WITTER, G. P.; SILVA, J. F. M. (Orgs.). Comunicação e produção científica: contexto, indicadores, avaliação. São Paulo: Angellara, 2006. p.33-55. 
DENES, G.; KOMATSU, B. K.; MENEZES-FILHO, N. Uma avaliação dos impactos macroeconômicos e sociais de programas de transferência de renda nos municípios brasileiros. Revista Brasileira de Economia, v. 72, n. 3, p. 292-312, jul./ set. 2018. Disponível em: http://www.scielo.br/scielo.php?script=sci_arttext\&pid =S0034-71402018000300292. Acesso em: 3 jan. 2019. http://dx.doi.org/10.5935/00347140.20180014

GIROTO, C. R. M.; SABELLA, N. M. M.; LIMA, J. M. R. Representações do professor generalista acerca do papel do professor especialista: análise da produção científica em educação especial no período de 2008 a 2015. Revista Educação Especial, Santa Maria, v. 32, p. 1-20, 2019. Disponível em: https://periodicos.ufsm. br/educacaoespecial/article/view/24254. Acesso em: 9 jan. 2019. http://dx.doi. org/10.5902/1984686X24254

GONÇALVES, G. Q.; MENICUCCI, T M. G.; AMARAL, E. F. L. Diferencial educacional entre beneficiários e não beneficiários do Programa Bolsa Família. Cadernos de Pesquisa, São Paulo, v. 47, n. 165, p. 770-795, jul./set. 2017. Disponível em: http:// www.scielo.br/scielo.php?script=sci_abstract\&pid=S0100-15742017000300001\&lng=e n\&nrm=iso\&tlng=pt. Acesso em: 12 jan. 2019. http://dx.doi.org/10.1590/198053144297 IBGE - INSTITUTO BRASILEIRO DE GEOGRAFIA E ESTATÍSTICA. Síntese de indicadores sociais: indicadores apontam aumento da pobreza entre 2016 e 2017. Rio de Janeiro: IBGE, 2018. Disponível em: https://agenciadenoticias.ibge. gov.br/agencia-sala-de-imprensa/2013-agencia-de-noticias/releases/23298-sintese-deindicadores-sociais-indicadores-apontam-aumento-da-pobreza-entre-2016-e-2017. Acesso em: 14 mar. 2019.

JANUZZI, P. M.; PINTO, A. R. Bolsa Família e seus impactos nas condições de vida da população brasileira: uma síntese dos principais achados da pesquisa de avaliação de impacto do Bolsa Família. In: CAMPELLO, T.; NERI, M. C. (Orgs.). Programa Bolsa Família: uma década de inclusão e cidadania. Brasília, DF: IPEA, 2013. p. 179-192.

MELO, R. M. S.; DUARTE, G. B. Impacto do Programa Bolsa Família sobre a Frequência Escolar: o caso da agricultura familiar no Nordeste do Brasil. Revista de Economia e Sociologia Rural, Brasília, v. 48, n. 3, p. 635-656, jul./set. 2010. Disponível em: http://www.scielo.br/scielo.php?script=sci_arttext\&pid $=$ S0103-20032010000300007. Acesso em: 23 jan. 2019. http://dx.doi.org/10.1590/ S0103-20032010000300007

NERI, M.Uma próxima geração de programas de transferência de renda condicionada. Revista de Administração Pública, Rio de Janeiro,v. 51, n. 2, p. 168-181, mar./abr. 2017. Disponível em: http://bibliotecadigital.fgv.br/ojs/index.php/rap/article/view/67720. Acesso em: 5 de jan. 2019.

PIRES, A. Afinal, para que servem as condicionalidades em educação do Programa Bolsa Família? Ensaio: avaliação e políticas públicas em educação, Rio de Janeiro, v. 21, n. 80, p. 513-532, jul./set. 2013. Disponível em: http://dx.doi.org/10.1590/S010440362013000300007. Acesso em: 8 jan. 2019.

SANTOS, E. A. Crianças da Bolsa Família nas escolas de Sinop. Revista Eventos Pedagógicos, Sinop, v. 7, n. 2, (19. ed.), p. 386-399, jun./jul. 2016. Disponível em: 
http://sinop.unemat.br/projetos/revista/index.php/eventos/article/view/2235. Acesso em: 6 jan. 2019. 10.30681/2236-3165

SILVEIRA, A. D.; SCHNEIDER, G. Política educacional, pobreza e educação: retrato do atendimento aos estudantes beneficiários do Programa Bolsa Família no Paraná. Educar em Revista, Curitiba, n. 2, p. 113-130, set. 2017. Disponível em: http://www.scielo.br/scielo.php?pid=S0104-40602017000600113\&script=sci abstract\&tlng=pt. Acesso em: 23 jan. 2019. http://dx.doi.org/10.1590/0104-4060.51391 TESTA, M. G.; FRONZA, P.; PETRINI, M.; PRATES,J.C. Análise da contribuição do Programa Bolsa Família para o enfrentamento da pobreza e a autonomia dos sujeitos beneficiários. Revista de Administração Pública, Rio de Janeiro, v. 47, n. 6, p. 519-541, nov./dez. 2013. Disponível em: http:/www.scielo.br/scielo.php?pid=S0034$76122013000600009 \&$ script=sci_abstract\&tlng=pt. Acesso em: 5 jan. 2019. http://dx.doi.org/10.1590/S0034-76122013000600009

VYGOTSKY, L. S. The genesis of higher mental functions. In: WERTSCH, J. V. (Ed.). The concept of activity in soviet psycology. New York: Sharpe, 1981.p. 144-189. YANNOULAS, S. C.; ASSIS, S. G.; FERREIRA, K. M. Educação e pobreza: limiares de um campo em (re)definição. Revista Brasileira de Educação, Rio de Janeiro, v. 17, n. 50, p. 329-351, maio/ago. 2012. Disponível em http://www.scielo.br/scielo. php?pid=S1413-24782012000200005\&script=sci_abstract\&tlng=pt. Acesso em: 22 fev. 2019. http://dx.doi.org/10.1590/S1413-24782012000200005

ZIMMERMANN, C. R.; ESPÍNOLA, G. M. Programas sociais no Brasil: um estudo sobre o Programa Bolsa Família no interior do Nordeste brasileiro. Cadernos CRH, Salvador, v. 28 , n. 73 , p. 147-164, jan./abr. 2015. Disponível em: www.scielo.br/pdf/ ccrh/v28n73/0103-4979-ccrh-28-73-0147.pdf. Acesso em: 28 jan. 2019. http://dx.doi. org/10.1590/S0103-49792015000100010

\section{SOBRE OS AUTORES}

Bárbara Amaral Martins é doutora em educação pela Universidade Estadual Paulista "Júlio de Mesquita Filho" (UNESP). Professora da Universidade Federal de Mato Grosso do Sul (UFMS).

E-mail:barbara.martins@ufms.br

Fabiano Quadros Rückert é doutor em história pela Universidade do Vale do Rio dos Sinos (UNISINOS). Professor da Universidade Federal de Mato Grosso do Sul (UFMS).

E-mail: fabianoqr@yahoo.com.br

Recebido em 4 de abril de 2019 Aprovado em 22 de jultho de 2019 